\title{
Influence of Lower Energy Levels on the First Ionization Potentials of Molecules of Oxygen-containing Compounds
}

\author{
M. Yu. Dolomatov ${ }^{1} \&$ K. F. Latypov ${ }^{1}$ \\ ${ }^{1}$ Department of Physics, Ufa State Academy of Economics and Service, Russian Federation \\ Correspondence: M. Yu. Dolomatov, Department of Physics, Ufa State Academy of Economics and Service, \\ 18-229 Davletshina st., 145 Chernyshevskiy St., Ufa 450077, Russian Federation. Tel: 7-917-437-9112. E-mail: \\ kamil-latipov@rambler.ru
}

Received: May 22, 2012 Accepted: June 2, 2012 Online Published: July 30, 2012

doi:10.5539/apr.v4n3p152 URL: http://dx.doi.org/10.5539/apr.v4n3p152

\begin{abstract}
In the family of molecules of oxygen-containing organic compounds correlation between the first empirically determined ionization potentials and the energies of deep-seated molecular orbitals has been calculated by the ab initio method of RHF-6-31G**. This dependence is observed in oxygen- containing compounds of different classes and is related to the exchange and Coulomb interaction of electrons. The results obtained were confirmed by statistical data processing.
\end{abstract}

Keywords: first ionization potential, integrated oscillator strength, electronic spectra, molecular orbitals energy, nitrogen-containing compounds, quantum chemistry

\section{Introduction}

Despite the existing methods developed in molecular quantum mechanics, there is a problem of electronic interactions quantification in molecular systems and solids that are related to the effects of mutual repulsion, mutual Coulomb and exchange interaction between electrons. There are some difficulties when solving this problem with the help of MO LCAO (molecular orbital linear combination of atomic orbitals) method by Rutan in Hartree-Fock approximation (Frank Jensen, 2007), or with the help of density functional method by Cohen (Frank Jensen, 2007) in the context of multi-electron molecular systems. Therefore, we use experimental methods of electronic phenomenological spectroscopy which is offered by Dolomatov (Dolomatov, 1989; Dolomatov et al., 2005), as the basis for the estimation of the first adiabatic ionization potential (IP), in particular the new methods based on UV-visible spectroscopy. The purpose of this study is to investigate correlation effects caused by the interaction of electrons in molecules, specifically the impact of deep-seated molecular orbitals (MO) on the first adiabatic IP.

\section{Experimental Procedure}

The objects chosen for investigation are oxygen-containing compounds of the series of xylenols, phenols, oxypyrenes, fluorenols, naphthols, methoxy-compounds, indanols (60 compounds). The choice of oxygencontaining compounds is determined by the fact that oxygen hetero atoms contribute significantly to the effects of electron correlation.

The first IPs has been estimated according to the integrated oscillator strength (IOS) in the UV and visible ranges (Dolomatov, 1989; Dolomatov \& Mukaeva, 1992; Dolomatov et al., 2012). The minimum IOS value in the examined series is $105,82 \cdot 10^{-7} \cdot \mathrm{m}^{3} * \mathrm{~mol}^{-1}$ for 2,6 -xylenol and the maximum value of $847,51 \cdot 10^{-7} \cdot \mathrm{m}^{3 *} \mathrm{~mol}^{-1}$ corresponds to 11-oxybenzo[b]pyrene.

Electronic spectra of compounds were observed in solutions of chemically pure ethanol in the absorption range of 200 to $500 \mathrm{~nm}$ in steps of $10 \mathrm{~nm}$, the spectra of phenols were selected from the corresponding databases (Bolshakov et al., 1969). The research into the spectra was conducted in quartz cells with an optical path length of $1 \mathrm{~cm}$, concentration of the substance amounting to $1 \mathrm{~g} / \mathrm{l}$. According to Koopmans' theorem the first IPs are treated as energies of the highest occupied MO (HOMO) with the opposite sign. For calculating the energy of MO, the ab initio method of RHF-6-31G** (Frank Jensen, 2007) with full optimization of the molecule geometry was chosen. 


\section{Results and Discussion}

The results of the experiment and calculations are listed in Table 1. Statistical data processing was performed by simple regression analysis with the estimation of the correlation coefficients and characteristics of the variation. Special program Phoenix-LD (certificate of registry №2012613372, 2012) in the Delphi 2010 programming environment was created for spectra processing. This program is designed to calculate the first IPs and electron affinity energy, as well as electronic states of atoms, molecules and nano-particles by means of electronic phenomenological spectroscopy. The program handles not only absorption spectra of various substances, but also corresponding luminescence spectra.

The correlation effect between the first IPs and deep-seated MO energies is presented as a linear matrix equation:

$$
\left(\begin{array}{l}
\varepsilon_{i 1} \\
\varepsilon_{i 2} \\
\ldots \\
\varepsilon_{i m}
\end{array}\right)=\left(\begin{array}{cc}
1 & -p_{11} \\
1 & -p_{12} \\
\ldots & \ldots \\
1 & -p_{1 m}
\end{array}\right)\left(\begin{array}{l}
\alpha_{1 i} \\
\alpha_{2 i}
\end{array}\right)+\left(\begin{array}{c}
\omega_{i 1} \\
\omega_{i 2} \\
\ldots \\
\omega_{i m}
\end{array}\right)
$$

Where $\varepsilon_{i j}$ - element of the column vector corresponding to the energy of the i-th MO in the j-th compound; $\alpha_{1 i-}$ energy of the $\mathrm{i}$-th $\mathrm{MO}$ with $\mathrm{p}_{1 \mathrm{j}}=0 ; \alpha_{2 i}$ - coefficient of the $\mathrm{i}$-th MO energy change with the energy of the corresponding level increasing by $1 \mathrm{eV} ; \mathrm{p}_{1 \mathrm{i}}$ - the first experimental IP of the i-th compound; $\omega_{i j}$ - disturbance parameter, that takes into account deviation of $\varepsilon_{i j}$ from the mean value $\mathrm{i}=2 \ldots \mathrm{n}, \mathrm{j}=1 \ldots \mathrm{m}$.

Table 1. First experimental IPs and calculated energies of MO

\begin{tabular}{|c|c|c|c|c|c|c|c|c|c|c|c|c|c|c|c|}
\hline Compound & $\begin{array}{c}\text { 1IP, } \\
\text { experim } \\
\text { ent, eV }\end{array}$ & $\begin{array}{l}\text { E2, } \\
\text { eV }\end{array}$ & $\begin{array}{l}\text { E3, } \\
\text { eV }\end{array}$ & $\begin{array}{l}\mathrm{E} 4, \\
\mathrm{eV}\end{array}$ & $\begin{array}{l}\text { E5, } \\
\text { eV }\end{array}$ & $\begin{array}{l}\text { E6, } \\
\text { eV }\end{array}$ & $\begin{array}{l}\text { E7, } \\
\text { eV }\end{array}$ & $\begin{array}{l}\text { E8, } \\
\text { eV }\end{array}$ & $\begin{array}{l}\text { E9, } \\
\text { eV }\end{array}$ & $\begin{array}{c}\text { E10, } \\
\text { eV }\end{array}$ & $\begin{array}{c}\text { E11, } \\
\text { eV }\end{array}$ & $\begin{array}{c}\text { E12, } \\
\text { eV }\end{array}$ & $\begin{array}{c}\text { E13, } \\
\text { eV }\end{array}$ & $\begin{array}{c}\text { E14, } \\
\text { eV }\end{array}$ & $\begin{array}{c}\text { E15, } \\
\text { eV }\end{array}$ \\
\hline phenol & 9.2 & -9.9 & -12.4 & -12.5 & -12.9 & -14.5 & -14.7 & -14.8 & -15.0 & -16.3 & -17.5 & -18.9 & -21.3 & -22.1 & -28.2 \\
\hline 0-Cresol & 9.1 & -9.7 & -12.3 & -12.4 & -12.7 & -13.6 & -13.9 & -14.5 & -14.6 & -15.1 & -15.2 & -16.2 & -17.5 & -18.6 & -21.1 \\
\hline $\mathrm{m}$-Cresol & 9.1 & -9.7 & -12.1 & -12.5 & -12.8 & -13.3 & -14.2 & -14.5 & -14.8 & -14.9 & -14.9 & -16.3 & -17.5 & -18.6 & -20.6 \\
\hline n-Cresol & 9.0 & -9.9 & -12.0 & -12.3 & -13.0 & -13.2 & -14.2 & -14.6 & -14.8 & -14.8 & -14.9 & -16.0 & -17.4 & -18.7 & -20.7 \\
\hline 2,3-xylenol & 9.0 & -9.4 & -12.0 & -12.3 & -12.7 & -13.1 & -13.7 & -13.8 & -14.2 & -14.5 & -14.6 & -15.0 & -15.4 & -16.1 & -17.5 \\
\hline 2,4-xylenol & 8.9 & -9.6 & -11.9 & -12.3 & -12.8 & -13.2 & -13.6 & -13.9 & -14.3 & -14.5 & -14.6 & -15.1 & -15.3 & -15.8 & -17.5 \\
\hline 2,5-xylenol & 9.0 & -9.5 & -11.9 & -12.4 & -12.8 & -13.1 & -13.7 & -13.8 & -14.4 & -14.4 & -14.5 & -15.1 & -15.3 & -16.2 & -17.4 \\
\hline 2,6-xylenol & 9.0 & -9.4 & -12.1 & -12.4 & -12.5 & -13.0 & -13.6 & -13.7 & -14.3 & -14.4 & -14.6 & -15.0 & -15.3 & -16.1 & -17.5 \\
\hline 3,4-xylenol & 8.9 & -9.6 & -11.8 & -12.2 & -12.5 & -13.2 & -13.7 & -14.0 & -14.3 & -14.5 & -14.7 & -15.0 & -15.1 & -16.1 & -17.4 \\
\hline 3,5-xylenol & 9.0 & -9.4 & -11.7 & -12.5 & -12.8 & -13.0 & -13.5 & -14.1 & -14.2 & -14.4 & -14.6 & -14.9 & -15.1 & -16.4 & -17.4 \\
\hline $\begin{array}{c}\text { 2,3,5-Trimethyl } \\
\text { phenol }\end{array}$ & 8.9 & -9.3 & -11.6 & -12.3 & -12.7 & -13.0 & -13.1 & -13.7 & -13.8 & -14.2 & -14.4 & -14.4 & -14.5 & -15.0 & -15.4 \\
\hline $\begin{array}{c}\text { 2,4,6-Trimethyl } \\
\text { phenol }\end{array}$ & 8.8 & -9.4 & -11.6 & -12.4 & -12.5 & -12.9 & -13.3 & -13.6 & -13.8 & -14.2 & -14.3 & -14.4 & -14.6 & -15.0 & -15.4 \\
\hline o-Ethylphenol) & 9.1 & -9.7 & -11.6 & -12.1 & -12.4 & -12.8 & -13.1 & -13.8 & -14.4 & -14.7 & -14.8 & -14.9 & -15.4 & -16.5 & -17.5 \\
\hline m-Ethylphenol & 9.1 & -9.7 & -11.8 & -12.2 & -12.2 & -12.7 & -13.2 & -14.1 & -14.4 & -14.6 & -14.7 & -15.0 & -15.4 & -16.5 & -17.6 \\
\hline n-Ethylphenol & 9.0 & -9.9 & -11.8 & -12.2 & -12.3 & -12.5 & -13.5 & -14.3 & -14.4 & -14.7 & -14.8 & -14.9 & -15.1 & -16.3 & -17.5 \\
\hline $\begin{array}{c}\text { 3-Methyl-5-eth } \\
\text { ylphenol }\end{array}$ & 9.0 & -9.5 & -11.8 & -11.9 & -12.2 & -12.9 & -13.0 & -13.2 & -14.1 & -14.2 & -14.4 & -14.6 & -14.9 & -15.0 & -15.5 \\
\hline $\begin{array}{l}\text { 4-Methyl-2,6-d } \\
\text { i-tret-butylphen } \\
\text { ol (BHT)) }\end{array}$ & 8.7 & -9.4 & -11.4 & -11.6 & -11.9 & -12.1 & -12.2 & -12.3 & -12.4 & -12.5 & -12.8 & -12.8 & -12.8 & -13.1 & -13.2 \\
\hline 4 Indanol & 9.0 & -9.4 & -11.6 & -12.5 & -12.6 & -12.7 & -13.0 & -13.1 & -13.8 & -14.4 & -14.6 & -14.9 & -15.0 & -16.3 & -16.6 \\
\hline
\end{tabular}




\begin{tabular}{|c|c|c|c|c|c|c|c|c|c|c|c|c|c|c|c|}
\hline 5 Indanol & 8.9 & -9.6 & -11.3 & -12.3 & -12.6 & -12.9 & -13.0 & -13.3 & -13.7 & -14.2 & -14.6 & -14.8 & -15.1 & -16.3 & -16.5 \\
\hline $\begin{array}{c}\text { 1,2,3,4-Tetrahy } \\
\text { dro-5-hydroxy- } \\
\text { naphthalene }\end{array}$ & 9.0 & -9.4 & -11.7 & -11.8 & -12.0 & -12.1 & -13.0 & -13.1 & -13.5 & -14.1 & -14.2 & -14.5 & -14.9 & -15.2 & -15.4 \\
\hline $\begin{array}{c}\text { 1,2,3,4-Tetrahy } \\
\text { dro-6-oxynapht } \\
\text { alene }\end{array}$ & 8.9 & -9.6 & -11.5 & -11.7 & -11.9 & -12.0 & -12.7 & -13.5 & -13.6 & -14.0 & -14.4 & -14.6 & -14.7 & -14.9 & -15.0 \\
\hline $\begin{array}{l}\text { o-cyclohexylph } \\
\text { enol }\end{array}$ & 9.1 & -9.7 & -10.7 & -11.2 & -11.5 & -12.2 & -12.3 & -12.4 & -12.5 & -13.1 & -13.3 & -13.6 & -13.7 & -14.0 & -14.6 \\
\hline $\begin{array}{c}\mathrm{n}- \\
\text { cyclohexylphe } \\
\text { nol }\end{array}$ & 9.0 & -9.9 & -11.2 & -11.4 & -11.6 & -11.9 & -12.0 & -12.3 & -12.5 & -13.1 & -13.6 & -14.0 & -14.2 & -14.4 & -14.7 \\
\hline o-phenylphenol & 8.8 & -9.4 & -10.0 & -10.7 & -12.0 & -12.5 & -12.6 & -12.9 & -13.2 & -13.5 & -14.2 & -14.3 & -14.8 & -15.0 & -15.1 \\
\hline n-phenylphenol & 8.6 & -9.8 & -10.0 & -10.2 & -11.8 & -12.5 & -12.6 & -12.8 & -13.4 & -13.6 & -14.3 & -14.5 & -14.6 & -14.8 & -15.2 \\
\hline 1-naphthol & 8.5 & -9.5 & -10.3 & -11.8 & -12.2 & -12.4 & -13.3 & -13.3 & -13.8 & -14.5 & -14.8 & -14.9 & -15.3 & -15.8 & -16.4 \\
\hline $\begin{array}{c}\text { 2-naphthol } \\
2\end{array}$ & 8.7 & -9.3 & -10.6 & -11.6 & -12.2 & -12.7 & -13.1 & -13.5 & -14.3 & -14.5 & -14.8 & -14.9 & -15.2 & -15.4 & -16.4 \\
\hline $\begin{array}{c}\text { naphthylcarbin } \\
\text { ol }\end{array}$ & 8.8 & -9.4 & -10.6 & -11.1 & -11.9 & -12.1 & -12.4 & -12.9 & -13.3 & -13.9 & -14.3 & -14.4 & -14.9 & -15.1 & -15.4 \\
\hline $\begin{array}{c}2- \\
\text { (1-naphthyl) } \\
\text { cyclohexano }\end{array}$ & 8.6 & -9.3 & -10.4 & -11.0 & -11.3 & -11.6 & -11.7 & -11.9 & -12.0 & -12.3 & -12.5 & -12.9 & -13.1 & -13.5 & -13.7 \\
\hline $\begin{array}{c}2- \\
\text { (1-naphthyl) } \\
\text { phenol }\end{array}$ & 8.7 & -9.2 & -9.3 & -9.9 & -10.5 & -11.8 & -12.0 & -12.3 & -12.6 & -12.7 & -13.0 & -13.2 & -13.7 & -13.8 & -14.4 \\
\hline $\begin{array}{c}2- \\
\text { (2-naphthyl) } \\
\text { phenol }\end{array}$ & 8.5 & -9.0 & -9.5 & -10.1 & -10.7 & -11.8 & -11.9 & -12.2 & -12.7 & -12.7 & -12.9 & -13.0 & -13.9 & -13.9 & -14.2 \\
\hline 1 Fluorenol & 8.8 & -9.2 & -9.7 & -10.5 & -12.3 & -12.4 & -12.6 & -12.8 & -13.0 & -13.0 & -14.3 & -14.3 & -14.5 & -14.7 & -14.9 \\
\hline 2 Fluorenol & 8.6 & -9.5 & -9.9 & -10.2 & -12.3 & -12.3 & -12.3 & -12.8 & -12.9 & -13.5 & -14.1 & -14.5 & -14.5 & -14.7 & -14.9 \\
\hline 9 Fluorenol & 9.0 & -9.8 & -9.9 & -10.6 & -11.4 & -12.2 & -12.6 & -12.6 & -13.0 & -13.2 & -13.4 & -13.8 & -14.8 & -14.8 & -15.1 \\
\hline $\begin{array}{l}\text { 4-Methyl-9-flu } \\
\text { orenol }\end{array}$ & 8.9 & -9.6 & -9.8 & -10.6 & -11.4 & -12.1 & -12.4 & -12.7 & -12.7 & -13.2 & -13.2 & -13.4 & -13.6 & -14.7 & -14.7 \\
\hline $\begin{array}{l}\text { 9-Methyl-9-flu } \\
\text { orenol }\end{array}$ & 8.9 & -9.7 & -9.9 & -10.6 & -11.4 & -12.0 & -12.4 & -12.6 & -12.8 & -12.9 & -13.4 & -13.5 & -13.5 & -14.3 & -14.7 \\
\hline $\begin{array}{l}\text { 9-Ethyl-9-fluor } \\
\text { enol }\end{array}$ & 8.9 & -9.7 & -9.9 & -10.6 & -11.2 & -11.8 & -12.2 & -12.5 & -12.6 & -12.9 & -13.0 & -13.1 & -13.5 & -13.8 & -13.9 \\
\hline $\begin{array}{c}9 \\
\text { Fluorenylcarbi } \\
\text { nol }\end{array}$ & 8.7 & -9.4 & -9.7 & -10.4 & -11.0 & -12.0 & -12.2 & -12.5 & -12.7 & -12.8 & -12.9 & -13.3 & -14.1 & -14.5 & -14.8 \\
\hline $\begin{array}{c}2 \text { - } \\
\text { (1-naphthyl)-1- }\end{array}$ & 8.2 & -8.9 & -9.3 & -9.6 & -10.4 & -10.8 & -11.7 & -11.7 & -11.9 & -12.2 & -12.5 & -12.7 & -12.8 & -13.4 & -13.5 \\
\hline naphthol & & & & & & & & & & & & & & & \\
\hline 1-oxypyrene & 8.1 & -9.1 & -10.0 & -10.1 & -10.9 & -12.0 & -12.3 & -12.4 & -12.7 & -13.0 & -13.4 & -13.7 & -14.1 & -14.1 & -14.3 \\
\hline 3-oxypyrene & 8.0 & -9.1 & -9.9 & -10.0 & -10.9 & -11.9 & -12.1 & -12.3 & -12.7 & -13.0 & -13.3 & -13.6 & -14.0 & -14.1 & -14.1 \\
\hline 3-oxypyrene & 8.0 & -9.1 & -9.9 & -10.0 & -10.9 & -11.9 & -12.1 & -12.3 & -12.7 & -13.0 & -13.3 & -13.6 & -14.0 & -14.1 & -14.1 \\
\hline 4-oxypyrene & 8.1 & -9.0 & -9.7 & -10.2 & -10.9 & -11.9 & -12.1 & -12.3 & -13.0 & -13.1 & -13.1 & -13.6 & -14.0 & -14.0 & -14.2 \\
\hline
\end{tabular}




\begin{tabular}{|c|c|c|c|c|c|c|c|c|c|c|c|c|c|c|c|}
\hline 4-oxypyrene & 8.1 & -9.0 & -9.7 & -10.2 & -10.9 & -11.9 & -12.1 & -12.3 & -13.0 & -13.1 & -13.1 & -13.6 & -14.0 & -14.0 & -14.2 \\
\hline \multicolumn{16}{|l|}{ 11-Oxybenzo } \\
\hline$[\mathrm{b}]$ & 8.0 & -8.9 & -9.5 & -9.8 & -10.5 & -10.9 & -11.7 & -12.0 & -12.4 & -12.4 & -12.6 & -13.1 & -13.4 & -13.6 & -13.7 \\
\hline \multicolumn{16}{|l|}{ pyrene } \\
\hline catechol & 8.8 & -9.7 & -12.2 & -12.8 & -12.9 & -13.6 & -14.1 & -15.0 & -15.1 & -15.1 & -15.8 & -17.6 & -18.2 & -19.0 & -21.2 \\
\hline resorcino & 9.1 & -9.5 & -12.0 & -12.6 & -13.4 & -14.2 & -14.2 & -14.8 & -15.0 & -15.2 & -16.1 & -17.2 & -18.0 & -19.3 & -21.8 \\
\hline \multicolumn{16}{|l|}{ 1,1-Bis (4- } \\
\hline $\begin{array}{l}\text { hydroxyphenyl } \\
\text { ) ethane }\end{array}$ & 9.0 & -9.1 & -9.8 & -9.9 & -11.8 & -11.9 & -12.2 & -12.5 & -12.6 & -12.8 & -13.4 & -13.5 & -14.0 & -14.5 & -14.6 \\
\hline \multicolumn{16}{|l|}{ 2,2-Bis } \\
\hline $\begin{array}{l}\text { (4-hydroxyphe } \\
\text { nyl)propane }\end{array}$ & 8.9 & -9.1 & -9.8 & -9.9 & -11.8 & -11.8 & -12.1 & -12.5 & -12.5 & -12.6 & -12.8 & -13.0 & -13.5 & -13.9 & -14.1 \\
\hline \multicolumn{16}{|l|}{1 - (o-tolyl) } \\
\hline \multicolumn{16}{|l|}{-1,1'-dihydroxy } \\
\hline \multicolumn{16}{|l|}{$\begin{array}{l}\text { ro-2,1'-dinapht } \\
\text { hyl }\end{array}$} \\
\hline \multicolumn{16}{|l|}{ 3,3',5,5'-Tetra-t } \\
\hline $\begin{array}{l}\text { ret-butyl-4,4'-di } \\
\text { hinoethan }\end{array}$ & \multicolumn{14}{|c|}{ hinoethan } & -12.4 \\
\hline anisole & 9.1 & -9.8 & -11.9 & -12.3 & -12.7 & -13.2 & -13.3 & -14.7 & -14.9 & -15.0 & -16.3 & -16.5 & -17.1 & -19.1 & -21.2 \\
\hline $\begin{array}{l}\text { 4-cyclohexilani } \\
\text { sole }\end{array}$ & 8.9 & -9.8 & -11.1 & -11.2 & -11.4 & -11.8 & -11.9 & -12.2 & -12.3 & -12.8 & -13.1 & -13.4 & -13.6 & -13.9 & -14.1 \\
\hline 2 & & & & & & & & & & & & & & & \\
\hline $\begin{array}{c}\text { Methoxydiphe } \\
\text { nyl }\end{array}$ & 8.7 & -9.4 & -9.8 & -10.6 & -11.8 & -11.9 & -12.0 & -12.5 & -13.0 & -13.1 & -13.2 & -13.8 & -14.0 & -14.5 & -14.9 \\
\hline $\begin{array}{c}\text { 4-phenylanisol } \\
\mathrm{e}\end{array}$ & 8.6 & -9.8 & -9.9 & -10.2 & -11.8 & -11.9 & -12.6 & -12.6 & -13.0 & -13.1 & -13.6 & -13.8 & -14.3 & -14.5 & -14.8 \\
\hline $\begin{array}{c}\text { 1-methoxy-nap } \\
\text { hthalene }\end{array}$ & 8.5 & -9.5 & -10.2 & -11.7 & -12.1 & -12.4 & -12.4 & -13.1 & -13.3 & -13.9 & -13.9 & -14.5 & -14.8 & -15.3 & -16.0 \\
\hline 5-methoxy-1,2, & & & & & & & & & & & & & & & \\
\hline $\begin{array}{c}\text { 3,4-tetrahydron } \\
\text { aphthalene }\end{array}$ & 8.9 & -9.4 & -11.0 & -11.6 & -11.8 & -12.1 & -12.5 & -12.8 & -13.1 & -13.3 & -13.4 & -13.5 & -14.5 & -14.8 & -14.9 \\
\hline $\begin{array}{c}\text { 1-methoxypyre } \\
\text { ne }\end{array}$ & 8.0 & -9.0 & -9.8 & -10.0 & -10.8 & -11.8 & -11.9 & -12.3 & -12.4 & -12.7 & -13.1 & -13.2 & -13.4 & -13.6 & -14.1 \\
\hline $\begin{array}{c}\text { 4-methoxypyre } \\
\text { ne }\end{array}$ & 8.1 & -9.0 & -9.6 & -10.2 & -10.8 & -11.6 & -12.0 & -12.2 & -12.7 & -13.0 & -13.0 & -13.1 & -13.1 & -13.6 & -13.9 \\
\hline $\begin{array}{c}\text { 7-methoxybenz } \\
\text { o [b] pyrene }\end{array}$ & 8.2 & -8.9 & -9.4 & -10.0 & -10.7 & -11.2 & -11.8 & -11.9 & -12.2 & -12.6 & -12.6 & -12.8 & -13.3 & -13.4 & -13.6 \\
\hline
\end{tabular}

The equation (1) can be rewritten as follows:

$$
\mathbf{E}_{\mathbf{i}}=\mathbf{P} \mathbf{1}_{\mathbf{i}} \times \mathbf{A}_{\mathbf{i}}+\mathbf{\Omega}_{\mathbf{i}}
$$

where $\mathbf{E}_{\mathbf{i}}$ is the column vector of the energy of $\mathrm{i}$-th $\mathrm{MO} ; \mathbf{P} \mathbf{1}_{\mathbf{i}}$ is the matrix of the experimental values of the first IPs in Koopmans' approximation; $\mathbf{A}_{\mathbf{i}}$ is the column vector of the empirical coefficients of electrons interactions, that characterizes energy changes of the i-th $\mathrm{MO} ; \Omega_{\mathrm{i}}$ is the column vector of disturbances that takes into account the deviation of Ei from the mean value; $i$ is the index of the MO under study. 
Proceeding from the well-known theorem of Gauss-Markov for the ordinary least squares (OLS), we can express the column vector of coefficients $\mathbf{A}_{\mathbf{i}}$ in terms of the following:

$$
\mathbf{A}_{\mathbf{i}}=\left(\mathbf{P} \mathbf{1}_{\mathbf{i}}^{\mathbf{T}} \times \mathbf{P} \mathbf{1}_{\mathbf{i}}\right)^{-\mathbf{1}} \times \mathbf{P} \mathbf{1}_{\mathbf{i}}^{\mathbf{T}} \times \mathbf{E}_{\mathbf{i}}
$$

The distribution of electrons energy in multi-electron systems is determined by the system of integro-differential equations in the Hartree-Fock approximation (Frank Jensen, 2007):

$$
F \phi_{i}=\varepsilon_{i} \phi_{i}
$$

where F - Fock operator, $\varepsilon_{i}-\mathrm{MO}$ energies.

Molecular orbitals $\varphi_{i}(\mu)$ are presented as LCAO $\chi_{i}(\mu)$

$$
\phi_{m}(\mu)=\sum C_{m i} \chi_{i}(\mu)
$$

where $\mathrm{C}_{\mathrm{mi}}$ - expansion coefficients.

$\chi_{i}$ is the basis for constructing molecular wave function $\varphi_{m}$.

Unknown coefficients $\mathrm{C}_{\mathrm{mi}}$ are defined using variational minimization of the total electron energy of the molecule. These coefficients are set by a system of nonlinear equations of Rutan (Ignatov, 2006):

$$
\sum_{j}\left(F_{i j}-\varepsilon_{m} S_{i j}\right) C_{m j}=0
$$

Where

$$
F_{i j}=\Phi_{i j}+\sum_{k, l} Q_{k l}\left(\langle i j \mid k l\rangle-\frac{1}{2}\langle i k \mid j l\rangle\right)
$$

given the normalization condition is:

$$
\sum_{i, j} C_{m i} C_{n j} C_{i j}=\delta_{m n}
$$

$\delta_{\mathrm{mn}}$-Kronecker delta

The summation is performed based on the entire array of basic sets $\mathrm{AO} \chi_{i}, \chi_{j}, \chi_{k} u \chi_{l}$

$\mathrm{S}_{\mathrm{ij}}$-interval of overlap AO $\chi_{i}$ и $\chi_{j}$;

$\Phi_{\mathrm{ij}}$-matrix element of the one-electron Hamiltonian, which takes into account the kinetic energy and the energy of electrons interreaction with other electrons and atomic nuclei;

$\mathrm{Q}_{\mathrm{kl}}$-density matrix, (charges and bonds orders);

$<\mathrm{ij} \mid \mathrm{k} \mathrm{l}>$ - integral of the Coulomb interaction between two electrons:

$$
<i j \mid k l>=\iint \chi_{i} \chi_{j}(1 / r) \chi_{k} \chi_{l} d \tau_{k} d r
$$

In the integrals (9), integration is performed within the entire space of Cartesian coordinates: $r$ - the distance between corresponding electrons.

Column vector Ei of the i-th MO energies in the approximation is obtained from the diagonal matrix of eigenvalues that is formed as a result of the Hartree-Fock operator diagonalization:

$$
\mathbf{C}^{-\mathbf{1}} \times E_{\mathbf{i}} \times \mathbf{C}=E_{\mathbf{i}}^{\mathbf{D}}
$$

where $\mathrm{C}$ - matrix consisting of the columns of the right eigenvectors of the $\mathbf{E}_{\mathbf{i}}$ matrix.

The diagonal matrix of eigenvalues is transformed into the column- vector of equations (1) by multiplying a row of integrity elements by the matrix: 


$$
\mathbf{E}_{\mathbf{i}}=\mathbf{z}_{\mathbf{i}}^{\mathbf{D}} \times \mathbf{E}_{\mathbf{1}},
$$

where $\mathbf{E}_{\mathbf{1}}=\left(\begin{array}{llll}1 & 1 & \ldots & 1\end{array}\right)$ - row- vector of integrity elements, the dimension of which coincides with the dimension of row-vector $\mathrm{E}_{\mathrm{i}}$

A statistical correlation coefficient is used as a measure of electron interaction, which is of the following form:

$$
\mathbf{R}=\left(\begin{array}{c}
r_{2} \\
r_{3} \\
\cdots \\
r_{n}
\end{array}\right)
$$

where R- column-vector of the correlation coefficients, the elements of which are the values of correlation coefficients ri for the investigated number of compounds, $\mathrm{i}-\mathrm{a}$ number of the HOMO, which is calculated as follows:

$$
r_{i}=\sqrt{1-\frac{\sum_{j=1 . . m}\left(-p_{1 j}-\varepsilon_{i j}\right)^{2}}{\sum_{j=1 . . . m}\left(-p_{1 j}-\bar{\varepsilon}\right)^{2}}}
$$

where $\bar{\varepsilon}$ - the mean of sample of energy sets of the i-th MO of the considered compounds.

Function $\mathrm{R}=\mathrm{f}\left(\mathrm{E}_{\mathrm{i}}\right)$ is nonlinear, asymmetric, uneven and multi-extremal. The values of correlation coefficients ri are in the range of $0,47 \leq r_{i} \leq 0,74$, which indicates that electrons of higher and lower orbitals of molecules interact with each other. In the family of oxygen-containing compounds within the limits of the RHF-6-31G** procedure, the maximum effect on the first IP is observed at the levels: $2(r=0,74), 8(r=0,76), 10(r=0,54), 14$ $(r=0,53)$; the minimum effect is at the levels: $3(r=0,67), 6(r=0,53), 9(r=0,53), 13(r=0,47)$.

Correlation of 15 MOs that covers a full range of oxygen-containing compounds is considered in this work. Figure 1 shows a graphical dependence of the correlation coefficient for the first IP and the energies of the lowest occupied MOs (including the 15-th level). The diagram indicates that the electrons of the molecules are linked into a single quantum system with a strong exchange and Coulomb interaction. The approximation of independent electrons by the Hartree-Fock method should take into account these disturbing effects.

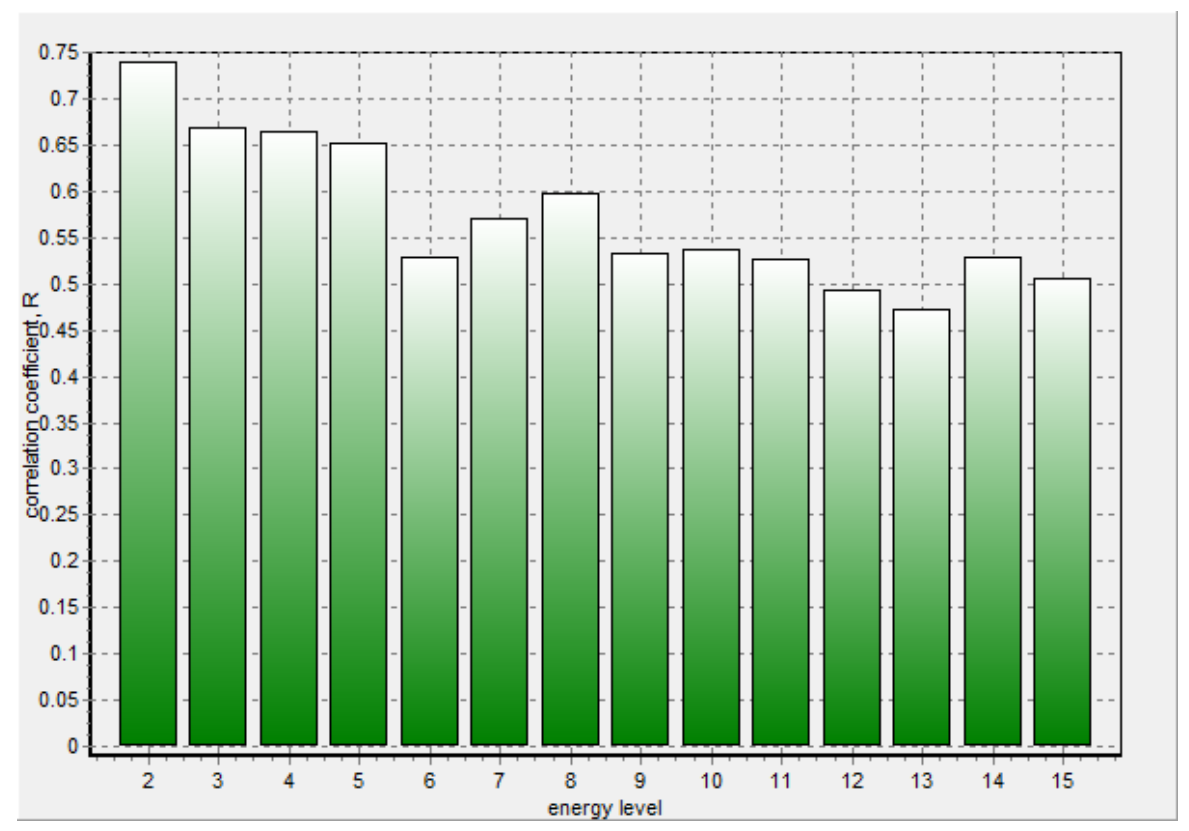

Figure 1. Diagram of correlation interaction 


\section{Conclusions}

1) There is a correlation of the first IP and the energies of lower MOs in the family of molecules of oxygen-containing compounds, which points to the fact that there is a strong electronic interaction between the external and internal atomic shells. It can be brought about by Coulomb and quantum electromagnetic effects. It is possible that the existence of such interactions is true for all energetic levels of molecules.

2) We have derived semi-empirical equations that connect the matrix of Hartree-Fock-Rutan with the first ionization potential and correlation energy of interaction between the external and internal electron shells of molecules. The established relationships can be used in quantum calculations of molecules and nano-electronics.

\section{References}

Bolshakov, G. F., Vatago, V. S., \& Agrest, F. B. (1969). Ultra-violet spectra of heterorganic compounds. Leningrad: Chemistry.

Certificate of registry №2012613372, day of entry: 10.04.2012, Russian Federation.

Dolomatov, M. Yu. (1989). Electronic spectroscopy application in physicochemical polycomponental stohastic mixtures and complex molecular systems. Russia, Ufa: Scientific and Technical Information center.

Dolomatov, M. Yu. (2005). Fragemts of real substanse theory. From hudrocarbon systems to galaxies. Moscow. Chemistry.

Dolomatov, M. Yu., \& Mukaeva, G. R. (1992). Method for determining the ionization potential and electron affinity of atoms and molecules using electron spectroscopy. Journal of Applied Spectroscopy, 56(4). http://dx.doi.org/10.1007/BF00665027

Dolomatov, M. Yu., Mukaeva, G. R., Jarmuhametova, G. U., \& Shulyakovskaya, D. O. (2009). Simple definition methods of electron structures of materials and molecules for nanoelectronics. Nanotech Europe, Berlin, Germany, 2009, 172.

Dolomatov, M. Yu., Shulyakovskaya, D. O., \& Jarmukhametova, G. U. (2010). Phenomenological spectroscopy estimation methods of electron structures molecules for Electronics. ELECMOL'10: 5-th International Meeting on Molecular Electronics, Grenoble, France, 255.

Dolomatov, M. Yu., Shulyakovskaya, D. O., Mukaeva, G. R., Jarmuhametova, G. U., \& Latypov, K. F. (2012). Simple characteristics estimation methods of material and molecule electronic structure. Journal of Materials Science and Engineering, 261-268.

Frank, Jensen. (2007). Introduction to Computational Chemistry (2nd ed.). The Atrium, Southern Gate, Chichester, West Sussex, England: John Wiley \& Sons, Ltd.

Ignatov, S. K. (2006). Quantum chemical modeling of molecular structure, physicochemical properties andreactivity. Part. 1. Nizhny Novgorod: Lobachevsky NS. 